\title{
Feeling the Emotions of Acted Characters: Commentary on Heisel
}

\author{
THALIA R. GOLDSTEIN [1] \\ Pace University
}

\begin{abstract}
This commentary addresses the hypothesis that empathy is a tool for embodiment and skillful performance in the presentation of opera and art song. It discusses the need to clearly and effectively define the term "empathy," and considers research from acting and theatre that speaks directly to how embodiment occurs in vocal performance, when that performance is attached to a character specifically. It concludes with some additional acting exercises singers may find useful.
\end{abstract}

Submitted 2014 September 26; accepted 2014 October 28.

KEYWORDS: empathy, theory of mind, acting, vocal performance, opera

WHERE do great performances come from? This question, in any performative art, whether music, dance, or acting, has almost as many answers as scholars. The question taken in Heisel's article and this commentary is whether "empathy" can be the road into a character, and whether this process is any different in the performance of an opera or art song than in acting in a theatrical work. First, however, empathy must be clearly defined and differentiated from other emotional and cognitive processes in performance.

\section{DEFINING EMPATHY}

Empathy has long been a complicated term to define in psychology - not least because of its use in lay language as well as scientific writings. In lay language, empathy is used in contexts from cognitively understanding what someone else is feeling and experiencing, to having compassion for another's pain. In between are a variety of definitions, including experiencing the emotions of another person, and regulating ones' own emotions to have an appropriate emotional reaction to another. This has caused some theorists and researchers to call for abandoning empathy as a term in the scientific language. Rather, empathy should be broken into its underlying components, and scholars should study and discuss those components instead. Those components could include: understanding others' mental and emotional states; concurrently feeling the emotions of another person; "catching" the emotions of another person through emotion contagion; and feeling sympathy or compassion for another's states (Batson, 2009; Coplan, 2011; Decety \& Cowell, 2014).

In trying to define what she means by the term empathy, Heisel (2015) comments directly on the notion of ridding our language of the term empathy, citing Gunkle's (1971) argument on empathy in theatrical audiences' reactions. Gunkle argued that empathy consists of such a large number of processes that using it as a catch-all term is essentially meaningless. Heisel comments that instead of not using the term, it should be placed in the aesthetic realm. Yet Gunkle's argument is not for the abandonment of empathy per se, but instead for clarification of its use and deeper thought about the psychological processes that underlie understanding a character's thoughts and feelings.

The idea behind the Gunkle quote is a correct one-we should determine exactly which definition of empathy Heisel is using in her exploration of empathy as a humanizing process for singers of opera and art song. As is often the case when discussing empathic processes, there are multiple definitions used here. The main one seems to be feeling oneself into the experience of another person in order to understand it, which is close to how most psychologists and neuroscientists would define "emotional empathy," "affective empathy," or "emotion sharing" (Decety \& Cowell, 2014). Another definition used is "reacting through the character's point of view," which could be considered closer to perspective taking (Keysar, Barr, Balin, \& Brauner, 2000), or seeing the world through another's eyes. Finally, "living the experience 
of the character," or responding to the character's situation as that person, could be considered taking on the experience of that character, or cognitively transporting the self into the narrative of the character (Green \& Brock, 2000; Kaufman \& Libby, 2012). Therefore, I would agree with Gunkle (and Decety, Coplan, Batson, and others) that even in the aesthetic realm, the term empathy should be used sparingly and only when strictly and well defined. It would serve better to talk about components and aspects of empathy separately.

The methods Heisel proposes to engage all of these processes under the term "empathy" are both physical and cognitive: embodiment of the physical states of the character, asking both how the character and singer are alike, and discovering what emotions the singer can understand, even when they cannot understand the subsequent behaviors of the character. Undertaking these processes, Heisel argues, will cause empathy (whether emotion sharing, perspective taking or experiencing taking), and therefore humanizing, identification, intimate knowledge, and real embodiment of the character.

This experience of empathy Heisel proposes is intimately connected to the physicalization of a character, to what she terms empathic embodiment (i.e. actually feeling the physical states and emotions of a character) rather than thinking one's way into the emotions of another person. Both are valid ways of empathizing with another, although psychology tends to focus on the mentalization of another's states, rather than beginning with physicalizing the experiences of another and coming to understand them somatically. However, this may be due to the methods usually used to measure empathy, which typically involve pencil and paper tests (e.g. Davis, 1983) or observations of behaviors (e.g. Zahn-Waxler et al., 1992). The idea of empathy working from the "outside-in" has been less studied.

In the end, any of these definitions of empathy lead to more questions: Does the singer merely need to understand emotions, or does he/she need to understand and then imagine feeling those emotions? At what point can the understanding be purely speculative, and at what point do the emotions need to relay back to the lived experiences of the singer? Can emotion ever exist purely without context? These questions have long been discussed by acting theorists, although not often in connection to psychological research and findings.

\section{CONNECTING EMBODIED EMPATHY BACK TO ACTING}

Empathy here is considered a "means by which singers closely identify with the characters they encounter and portray in opera and art song" (p. 105). But the question of "identify with" is also a tricky one. It could mean understanding what the character is going through; understanding and then finding similarities to their own life; or reframing singers' own self and experiences to react to the various events the character undergoes. Any or all of these could be ways in which to discover how the performer is similar to their character, and therefore feel the emotions of his or her character.

Acting theorists have offered a variety of arguments on how best to bridge the distance between a character's and performer's selves. Lee Strasberg (Hull, 1985) (derived from Stanislavski [1936]), believed actors must use their own emotions, from their own previous experiences, and re-experience those emotions onstage. This is contrasted with Stella Adler, who believed actors should imagine how they would react if the events had happened to them and portray those imagined emotions (Adler, 2000), and Sanford Meisner, who believed actors should simply respond with truth as a person, by paying close attention to the situation occurring in the play, rather than pulling emotions from elsewhere or from imagination (Meisner \& Longwell, 1987). Most modern acting training is a combination of these techniques, together with more physical methods of training the body to look as if it were in various states, so the audience can read what the character is feeling (Hodge, 2000). Most actors find individual aspects of each theory that work for them. Many may even change how they prepare dependent on the role or type of work presented.

The question is then should we think about singer training in the same way we think about acting and actor training? Is there a difference between acting a role in song and acting a role in word? As long as the instrument is the self, and there is a "character," does it matter? Although singers have the additional separation from the real world of singing rather than acting, as long as a realistic portrayal of an emotional state is the ultimate goal, I would argue that there are not many differences. A theory of empathy for music performance should build from a theory of empathy for acting performances, with the requisite arguments about the necessity of bringing in personal emotion and how the emotional body of the performer should be affected. Just as there are a variety of theories and techniques acting theorists use to think about the best way for a performer to understand and portray the emotional life, physical states, and mental states of a 
character, so should singers think about the best way to achieve the technical feats they must accomplish while being true to character.

Singers should study their characters as actors do. The difference is in the physicalization of the performance. Actors simulate and imagine what is happening to the character and then physicalize the words. Singers must simulate and imagine and then physicalize the words in a way that is not common in everyday life - through song. However, singers and actors are aided by the fact that songs and characters are created to be performed - they lack the psychological "messiness" of real people. They are created streamlined, without wasted words, actions, or emotions. Fiction is created as an abstraction of the social world (Mar \& Oatley, 2008), which in many ways makes empathy with characters easier than empathy with real people, whose stories are necessarily more complex.

In other words, opera and art song singers should become actors when creating a character that they then sing. Heisel proposes that the most intimate musical experience takes place between the character and his or her performer - this is not dissimilar to actors. In this way, singers can and should also benefit from other aspects of acting theory, research, and practice.

\section{RELATED ISSUES IN ACTING AND EMPATHY}

Additional long-examined questions in the study and practice of acting arise when applied to acting in song. An often debated question is whether it is better to perform and let the emotions of the character arise through the act of physicalizing and enacting them (from the "outside-in"), or whether it is better to first think through the emotions and use thoughts as a way to get to the performance (from the "inside-out"). Left unclear in Heisel's article is an opinion about whether there is a difference between these two modes, and whether it would make a difference in the performance itself. However, this is not a resolved question in acting theory either, with different teachers and actors approaching the order of emotional events differently, and psychologists having, up to this point, mostly ignored the question. We do know, however, that merely physicalizing an emotion, without any intention of feeling can cause physiological and experienced changes (Flack, 2006; Flack, Laird, \& Cavallaro, 1999). These feedback effects have been shown to affect individuals even when they do not know why they are being put into physical positions. A famous example is when people put a pen between their teeth to force their mouth into a smile: this causes people to think comics are funnier, as well as to report more happiness (Strack, Martin, \& Stepper, 1988). Individuals put into poses that denote power (e.g. arms spread wide, chest puffed out) report not only feeling more powerful, but also being more likely to take risks. These participants also show increases in testosterone (Carney, Cuddy, \& Yap, 2010). So while the entrance into the emotional state may be different (purposefully feeling an emotion versus physicalizing first), the end result may be the same.

The author also brings up a debate taken on by Diderot and Archer (Archer 1888/1957; Diderot, 1883/1957): does the performer need to feel the same level of emotional engagement as the character, or will that actually stop the performance from being effective? Diderot argued that actors must "pull the strings" of their characters, not actually feeling anything while crying real tears for an audience. Archer, however, argued that the best performances come when the actor is personally invested in the emotional presentation they are giving onstage. Work by Konijn (2000) with actors in the Netherlands proposes that actors must instead focus on task emotions, such as finding light, or for singers, hitting notes and having power behind their voices, rather being so wrapped up in the emotional sense of the song they are unable to actually perform it. Someone in the depths of heartbreak, sobbing for their loved one, is unlikely to be able to sustain a seven-minute aria. Empathy necessarily has a component of personal distress, because it involves feeling emotions that may be context-independent. It is the regulation of that personal distress that allows empathy with the character to be a performance, rather than to be so upsetting it becomes impossible to continue to portray the character. This is another reason to consider and measure the various components of empathy carefully and separately.

\section{EXERCIZES TO AID PERFORMANCE}

So how does a singer come to understand, experience and control the emotions of his or her character? Heisel recommends that singers who want to engage empathically with their performed characters use a journal to chronicle their character. Similarly, most acting students are asked to keep a "role journal" or "character journal." This is not only to document the processes of cognitively understanding and creating a 
particular role or scene, but also to think about impressions of other humans generally. As such, other exercises actors find useful when learning how to create characters may also be useful to singers.

For example, actors will often be tasked with finding real people on the street and figuring out how they walk and move, and then mimicking and performing those people in class. This teaches actors to pay close attention to the physicality of other people, while also teaching them how to think about their own bodies and how to move them in new ways. An additional exercise in this vein is for an actor to pair with another person, look at them carefully, and then look away. While looking away, the observed person changes a few things about themselves, to see if the partner notices. In this way, actors learn to look at the details of other humans, so as to be prepared to recreate them. Finally, actors have also long used mask work to help them create characters (Watson, 2013). In mask work, actors put on a grotesquely emotional mask and spend time in front of a mirror, determining how to make the rest of their body look and move as if it matches the character and expression of the mask. Then, actors work in groups, all wearing masks, and improvise how to interact in those characters. In this way, actors can try on different physical states and learn how various bodily movements and positions look to others.

\section{CONCLUSION}

Empathy (that is, feeling the emotions of a character) can be a fruitful way of looking at performance in music, particularly when the singer must portray a specific character. However, scholars and practitioners alike should be careful to define what they mean by empathy. The process of understanding a character's emotions, feeling those emotions, and controlling one's own emotions in response should be considered separately. Additionally, the best and most effective way to experience the emotions of a character remains open to debate and study. Singers and performers of all kinds would do well too to look to the acting literature and scholarship for guidance as to how to create and embody character in a full, truthful, and skilled way for an audience.

\section{ACKNOWLEDGEMENTS}

This publication was partially made possible through the support of a grant from the John Templeton Foundation. The opinions expressed in this publication are those of the author and do not necessarily reflect the views of the John Templeton Foundation. The author thanks Annie Levy for discussions on empathy and acting theory.

\section{NOTES}

[1] Correspondence can be addressed to: Dr. Thalia R. Goldstein, Pace University, Department of Psychology, 41 Park Row, 13 ${ }^{\text {th }}$ Floor, NY, NY 10038, tgoldstein@pace.edu.

\section{REFERENCES}

Adler, S. (2000). The art of acting. New York: Hal Leonard Corporation.

Archer, W. (1888/1957). Masks or faces. Denis Diderot, the paradox of acting and William Archer, masks or faces. New York: Hill and Wang.

Batson, C. D. (2009). These things called empathy: Eight related but distinct phenomena. In J. Decety \& W. Ickes (Eds.), The social neuroscience of empathy (pp. 3-15). Cambridge, MA: MIT press.

Carney, D. R., Cuddy, A. J., \& Yap, A. J. (2010). Power posing: Brief nonverbal displays affect neuroendocrine levels and risk tolerance. Psychological Science, 21(10), 1363-8. doi: $10.1177 / 0956797610383437$

Coplan, A. (2011). Will the real empathy please stand up? A case for a narrow conceptualization. The Southern Journal of Philosophy, 49(s1), 40-65. 
Davis, M. H. (1983). Measuring individual differences in empathy: Evidence for a multidimensional approach. Journal of Personality and Social Psychology, 44(1), 113-126.

Decety, J., \& Cowell, J. M. (2014). The complex relation between morality and empathy. Trends in Cognitive Sciences, 18(7), 337-339.

Diderot, D. (1883/1957). The paradox of acting. Denis Diderot, the paradox of acting and William Archer, masks or faces. New York: Hill and Wang.

Flack, W. (2006). Peripheral feedback effects of facial expressions, bodily postures, and vocal expressions on emotional feelings. Cognition \& Emotion, 20(2), 177-195.

Flack, W. F., Laird, J. D., \& Cavallaro, L. A. (1999). Separate and combined effects of facial expressions and bodily postures on emotional feelings. European Journal of Social Psychology, 29(2-3), 203-217.

Green, M. C., \& Brock, T. C. (2000). The role of transportation in the persuasiveness of public narratives. Journal of Personality and Social Psychology, 79(5), 701-721. doi:10.1037//0022-3514.79.5.701

Gunkle, G. (1971). Empirical research in theatre: State of the art, 1970. Educational Theatre Journal, 23(2), 171-177.

Hodge, A. (2000). Twentieth-centuy actor training. Psychology Press.

Heisel, E. (2015). Empathy as a tool for embodiment processes in vocal performance. Empirical Musicology Review, 10(2), 104-110.

Hull, S. L. (1985). Strasberg's method as taught by Lorrie Hull: A practical guide for actors, teachers, and directors. Oakville, CT: Ox Bow Publishers.

Kaufman, G. F., \& Libby, L. K. (2012). Changing beliefs and behavior through experience-taking. Journal of Personality and Social Psychology, 103(1), 1-19. doi:10.1037/a0027525

Keysar, B., Barr, D. J., Balin, J. A., \& Brauner, J. S. (2000). Taking perspective in conversation: The role of mutual knowledge in comprehension. Psychological Science, 11(1), 32-8.

Konijn, E. (2000). Acting emotions: Shaping emotions on stage. Amsterdam, The Netherlands: Leiden University Press.

Mar, R. A., \& Oatley, K. (2008). The function of fiction is the abstraction and simulation of social experience. Perspectives on Psychological Science, 3(3), 173.

Meisner, S., \& Longwell, D. (1987). Sanford Meisner on acting. New York: Vintage.

Stanislavski, K. (1936). An actor prepares. New York: A Theatre Arts Book, Routledge.

Strack, F., Martin, L. L., \& Stepper, S. (1988). Inhibiting and facilitating conditions of the human smile: A nonobtrusive test of the facial feedback hypothesis. Journal of Personality and Social Psychology, 54(5), 768.

Watson, I. (2013). Performer training: Developments across cultures. New York: Routledge.

Zahn-Waxler, C., Radke-Yarrow, M., Wagner, E., \& Chapman, M. (1992). Development of concern for others. Developmental Psychology, 28, 126-136. 